\title{
Some Biological Aspects and Influence of Male and Female Presence Period on the Fecundity of Steatoda triangulosa Walckenaer, (Araneae: Theridiidae)
}

\author{
Sherin, H. M. Safar and M. F. R. Mahmoud \\ Plant Protection Dept., Fac. of Agric. Fayoum Univ., Fayoum, Egypt.
}

\begin{abstract}
Some biological aspects of the spider Steatoda triangulosa were recorded upon feeding on Tribolium confusum larvae, it passed through four spiderlings for female and three spiderlings for male before reaching adult. The total spiderlings duration averaged $(28.8,24.2$ days) consuming $(36.8,23.7$ larvae) for female and male under laboratory conditions (23$35^{\circ} \mathrm{C}$ and 46-60 \% R.H.). To determine the influence of male and female presence period, the experiment was performed with three different cases, in which the presence period of the first case was for one day; while the second was for seven days and the third case was conducted as females without males. Data illustrated that the number of eggs/female increased according to the increasing in this period recorded 71.6, 90.2 and 17.4, respectively. Longevity, life span and number of egg sacs deposited by females were independent of the females' mating status in $1^{\text {st }}$ and $2^{\text {nd }}$ cases as there are no significant differences between them; while the $3^{\text {rd }}$ case was significantly different.
\end{abstract}

Key words: Steatoda triangulosa, male and female presence period, Fecundity, Biological aspects.

\section{INTRODUCTION}

Spiders hold a very prominent position in environment especially in maintenance of ecosystem. Members of the family Theridiidae are small to medium size. They are usually found hanging upside down in an irregular web suspended on plants or hidden in rock crevices or fissures in soils (Levy 1998 and El-Erksousy 2000). In Egypt, some species of this family were usually found in different field and truck crops and orchards. Due to its spread and importance, El-Erksousy 2003, El-Erksousy et al., 2006 and Hussein et al., 2003 studied the biology of three species of this family. Genus Steatoda includes key species that regulate population of insects (Maelfait and Hendrickx, 1998).

Steatoda triangulosa is a predominant species on different crops at Fayoum Governorate (Rahil 2001 and Mahmoud 2004).

The present work sheds light on the influence of male and female presence period on female fecundity to obtain the greatest number of individuals in the shortest period to facilitate the mass rearing of spider as the spider is considered an important biocontrol agent.

\section{MATERIALS AND METHODS}

\section{1- Culture of spider:}

Females of the spider $S$. triangulosa were collected from field plants and transferred to the lab and maintained individually in 40 Petri dishes (10 $\mathrm{cm}$ ) provided with larvae of the flour beetle Tribolium confusum as food to prevent cannibalism under laboratory conditions $\left(23-35^{\circ} \mathrm{C}\right.$ and $46-60 \%$ R.H.). Females copulated before collection oviposited in few days and resultant immatures were left until adulthood and separated after being copulated. The newly deposited oothecae remained with mothers until hatched to be the source of individuals for the experiment.

\section{2- Culture of prey:}

Individuals of $T$. confusum were reared on wheat flour. Adult beetles were transferred from old flour samples to maintain culture of prey. Different instar larvae were used for spider feeding.

\section{3- Biological aspects of the spider:}

Emerged spiderlings were singly transferred to plastic units ( $25 \mathrm{~mm}$ diameter and $15 \mathrm{~mm}$ height) to be fed on prey and were daily observed until maturity.

Fifty newly hatched spiderlings were singly fed with surplus prey and daily observed through the durations of different developmental stages, and registering numbers of prey individuals consumed.

Influence of male presence with female on fecundity was examined. Immediately after the last molt, females were allowed copulation by introducing a male to each female. For this purpose, 50 replicates were divided to 3 cases; the first contained ten pairs of females and males for one day, the second contained ten pairs for seven days and the third contained ten females only as male was absent. Females were observed to register number of egg sacs/female, eggs/sac and \% hatchability, also the periods of pre, ovi and post oviposition.

\section{RESULTS AND DISCUSSION}

Spider females of S. triangulosa differ than males in number of spiderlings, females have4; while males have 3 spiderlings when fed on larvae of Tribolium confusum under laboratory conditions at $23-35^{\circ} \mathrm{C}$ and 46-60 \% R.H. 


\section{A) Female durations:}

\section{a) Spiderlings:}

As shown in Table (1), S. triangulosa passed through four spiderlings to reach adulthood, the first lasted about 7.5 days, the second 5.8 days and the third and the fourth were 7.67 and 7.8 days, respectively, with total of 28.8 days ranging 24-34 days. Data also showed that the longest period was evident with $4^{\text {th }}$ spiderlings (7.8 day); while the lowest was (5.8 days) with $2^{\text {nd }}$ spiderlings.

\section{b- Adults:}

Data in table 2 indicated that there are three female longevities. The first was presence of male with female for one day, longevity of female was 209.5 days ranging 160-240 days and divided into three periods, pre-oviposition, oviposition and postoviposition periods recorded 10.9, 67.9 and 34.2 days, respectively; while the second case was the presence of female with male for seven days, the previous periods recorded 7.4, 79.7 and 61.3 days, respectively and longevity was 148.4 days. The third case was (female without male) and the previous periods recorded 40.1, 5.6 and 34 days, respectively; while longevity was 79.7 days. The previous data indicated that longevity and life span obtained in the second case was the longest; while the shortest obtained in the third case.

In this respect, pre-oviposition, oviposition and post-oviposition periods of the Steatoda paykulliana female averaged 6.82, 25.28 and 68.5 days, respectively, when fed on the newly emerged larvae of Spodoptera littoralis and consumed during these periods about 22.0, 68.8 and 90.22 prey/female/day, respectively (Abo-Zaed, 2014).

\section{B) Female food consumption: a) Spiderlings:}

The food consumption of the spiderlings increased with its growth (Table 1). The total number of prey consumed during four spiderlings (36.8 larvae). The number of prey consumed were 7.8, 7.17, 9.03 and 12.72 larvae during 1 st, 2 nd, $3 \mathrm{rd}$ and $4^{\text {th }}$ spiderlings, respectively.

\section{b) Adults:}

As shown in Table (3), total number of prey consumed during oviposition period is significantly different and averaged 138.2, 177.8 and 15.7 of the aforementioned case, respectively. There are significant differences between $3^{\text {rd }}$ case and the two other cases in pre-oviposition period, longevity and life span.

\section{c) Female fecundity:}

Female deposited an average of 8.6, 8.4 and 1.7 sacs/female with number of eggs/sac 71.6, 90.2 and 17.4 eggs with hatchability of $34.11,63.69$, respectively. Mating and presence period of male with female were necessary for egg fertility as well as increasing number deposited eggs.

$\mathrm{Wu}$, et al., 2013 studied the effects of sexual cannibalism on the fecundity of cannibalistic females and the survival of their offspring were tested. Our results indicated that sexual cannibalism affected positively the offspring survival of cannibalistic females, but not fecundity.

Table 1: Durations and food consumption of S. triangulosa female spiderlings

\begin{tabular}{ccccc}
\hline \multirow{2}{*}{ Spider lings } & \multicolumn{2}{c}{ Duration } & \multicolumn{2}{c}{ Food consumption } \\
\cline { 2 - 5 } & $\mathrm{M} \pm \mathrm{SE}$ & Range & $\mathrm{M} \pm \mathrm{SE}$ & Range \\
\hline $1^{\text {st }}$ & $7.5 \pm 0.31$ & $5-11$ & $7.8 \pm 0.24$ & $4-10$ \\
\hline $2^{\text {nd }}$ & $5.8 \pm 0.23$ & $4-8$ & $7.17 \pm 0.28$ & $5-10$ \\
\hline $3^{\text {rd }}$ & $7.67 \pm 0.23$ & $5-10$ & $9.03 \pm 0.47$ & $6-15$ \\
\hline $4^{\text {th }}$ & $7.8 \pm 0.29$ & $5-11$ & $12.77 \pm 0.66$ & $8-21$ \\
\hline Total & $28.8 \pm 0.6$ & $24-34$ & $36.8 \pm 0.85$ & $28-47$ \\
\hline
\end{tabular}

Table 2: Adult female durations of $S$. triangulosa influenced by presence of female with male

\begin{tabular}{lccccc}
\hline $\begin{array}{c}\text { Presence of } \\
+ \text { with }{ }^{\lambda}\end{array}$ & $\begin{array}{c}\text { Pre- } \\
\text { oviposition }\end{array}$ & Oviposition & $\begin{array}{c}\text { Post- } \\
\text { oviposition }\end{array}$ & Logevity & Life span \\
\hline 1 day & $10.9 \pm 0.62^{\mathrm{b}}$ & $67.9 \pm 2.4^{\mathrm{b}}$ & $34.2 \pm 2.43^{\mathrm{a}}$ & $113.0 \pm 3.03^{\mathrm{b}}$ & $141.2 \pm 2.82^{\mathrm{b}}$ \\
& $8-14$ & $50-77$ & $23-46$ & $101-130$ & $127-157$ \\
\hline 7 days & $7.4 \pm 0.93^{\mathrm{b}}$ & $79.7 \pm 3.6^{\mathrm{a}}$ & $61.3 \pm 3 .^{19 \mathrm{~b}}$ & $148.4 \pm 6.33^{\mathrm{a}}$ & $179.0 \pm 6.5^{\mathrm{a}}$ \\
& $5-12$ & $61-97$ & $49-77$ & $119-177$ & $143-206$ \\
\hline${ }^{\circ}$ alone & $40.1 \pm 1.93^{\mathrm{a}}$ & $5.6 \pm 1.28^{\mathrm{c}}$ & $34.0 \pm 3.22^{\mathrm{a}}$ & $79.7 \pm 4.58^{\mathrm{c}}$ & $107.3 \pm 4.35^{\mathrm{c}}$ \\
& $33-50$ & $1-10$ & $22-51$ & $62-111$ & $86-136$ \\
\hline
\end{tabular}


Table 3: Effect of presence of male on female longevity

\begin{tabular}{lccccc}
\hline $\begin{array}{c}\text { Presence of } \\
q \text { with }{ }^{\lambda}\end{array}$ & $\begin{array}{c}\text { Pre- } \\
\text { oviposition }\end{array}$ & Oviposition & $\begin{array}{c}\text { Post- } \\
\text { oviposition }\end{array}$ & Logevity & Life span \\
\hline 1day & $21.5 \pm 1.68^{\mathrm{b}}$ & $138.2 \pm 6.42^{\mathrm{b}}$ & $49.8 \pm 3.55^{\mathrm{a}}$ & $209.5 \pm 8.73^{\mathrm{a}}$ & $248.8 \pm 3.55^{\mathrm{a}}$ \\
& $15-30$ & $113-160$ & $33-70$ & $166-240$ & $33-70$ \\
\hline 7 days & $15.5 \pm 1.55^{\mathrm{b}}$ & $177.8 \pm 9.71^{\mathrm{a}}$ & $35.0 \pm 2.43^{\mathrm{b}}$ & $228.3 \pm 9.95^{\mathrm{a}}$ & $266.1 \pm 10.33^{\mathrm{a}}$ \\
& $10-25$ & $138-230$ & $25-48$ & $189-285$ & $223-323$ \\
\hline \% alone & $69.0 \pm 3.04^{\mathrm{a}}$ & $15.7 \pm 2.38^{\mathrm{c}}$ & $36.5 \pm 3.23^{\mathrm{b}}$ & $121.2 \pm 5.47^{\mathrm{b}}$ & $154.5 \pm 5.67^{\mathrm{b}}$ \\
& $59-85$ & $7-30$ & $20-50$ & $106-154$ & $134-187$ \\
\hline
\end{tabular}

Table 5: Whole life span and food consumption of S. triangulosa males

\begin{tabular}{|c|c|c|c|c|c|}
\hline \multirow{2}{*}{\multicolumn{2}{|c|}{ Male }} & \multicolumn{2}{|c|}{ Duration } & \multicolumn{2}{|c|}{ Food consumption } \\
\hline & & $\mathrm{M} \pm \mathrm{SE}$ & Range & $\mathrm{M} \pm \mathrm{SE}$ & Range \\
\hline \multirow{4}{*}{$\begin{array}{l}\stackrel{00}{\Xi} \\
\stackrel{0}{0} \\
\frac{\overrightarrow{0}}{\tilde{n}}\end{array}$} & $1^{\text {st }}$ & $9.6 \pm 0.4$ & $8-11$ & $8.2 \pm 0.53$ & $6-11$ \\
\hline & $2^{\text {nd }}$ & $6.6 \pm .045$ & $5-9$ & $6.3 \pm 0.52$ & $3-8$ \\
\hline & $3^{\text {rd }}$ & $8.5 \pm .062$ & $6-12$ & $9.2 \pm 0.59$ & $6-12$ \\
\hline & Total & $24.2 \pm 0.66$ & $21-28$ & $23.7 \pm 0.68$ & $19-27$ \\
\hline \multicolumn{2}{|c|}{ Adult longevity } & $155.8 \pm 15.3$ & $80-203$ & $119.8 \pm 6.98$ & $61-140$ \\
\hline \multicolumn{2}{|c|}{ Total life span } & $180.0 \pm 15.15$ & $106-226$ & $143.57 \pm 6.93$ & $85-162$ \\
\hline
\end{tabular}

Also, in the wolf spider, Schizocosa ocreata (Hentz), (Araneae, Lycosidae) to determine if females mate more than once, and to what degree copulation influences subsequent female mating, a multiple mating experiment was conducted, most females mated only once (93\%) and There was no difference between re-mating treatments ( 1 day, 3 days and 30 days) (Stephanie and George, 2005).

\section{D) Male duration: \\ a- Spiderling:}

It passed through three spiderlings (instars) to reach adulthood; lasted an average of 9.6, 6.6 and 8.5 days, respectively with total of 28.8 days ranging between 24 and 34 days. The previous data indicated that the longest period was evident with $3^{\text {rd }}$ spiderling (7.8 day) and the lowest was (5.8 days) with $2^{\text {nd }}$ spiderling.

\section{b- Adult:}

Longevity of male lasted for 155.8 days; while the duration of whole life span averaged 180 days.

\section{E) Male food consumption: a- Spiderlings:}

The total number of prey consumed by a spiderling was23.7 larvae with average of 8.2, 6.3, 9.2 and larvae during $1 \mathrm{st}, 2^{\text {nd }}$ and $3^{\text {rd }}$ spiderlings, respectively.

\section{b- Adult:}

The total number of prey consumed during adult longevity was 119.8 larvae with average of 143.57 larvae during the whole life span.

\section{REFERENCES}

Abo-Zaed, E., A., 2014. Biology of the Theridiid spider Steatoda Paykulliana (Walckamaer) when Fed on $1^{\text {st }}$ larvae instar of cotton leaf worm Spodoptera littoralis (Boisd.). East Journal of Applied Sciences, 4(1): 96-99.

El-Erksousy, M. H. 2000. Studied on some true spider in Egypt .Ph. D. Thesis, Fac. of Agric., Al-Azhar Univ. 130 pp.

El-Erksousy, M. H. 2003. Biology of the spider Theridion egyptium Fawzy \& El-Erksousy fed on Spodoptera littoralis larvae. Bull. Ent. Soc. Egypt, 80: 229-233.

El-Erksousy, M. H.; Shoeib, Ameira M. and Gomaa, Wafaa, O. 2006. Biological of the spider, Steatoda triangulosa (Walckenare) fed on larvae of Spodoptera littoralis (Boisd). ${ }^{\text {nd }}$ Conf., on Farm. I.P.M. 16-18. Jan.: 256-259.

Hussein, A. M.; Hassan, M. F. and Ahmed. N. F. R. 2003. Biological aspects of Anelosimus aulicus (C.L. Koch, 1838) (Arachnida: Araneida: Theridiidae) in Egypt. Serket, 8(4): 129-134.

Levy, G. 1998. Fauna Palestine. Arachnidae, Araneae: Theridiidae. The Israel Academy of sciences and Humanities, 225 pp.

Maelfait, J. P. and Hendrickx. F.1998. Spiders as bioindicators of anthropogenic stress in natural and semi-natural habitats in Flanders (Belgium): some recent developments. Proceedings of the European Colloquium of Arachnology, 17: 293-300.

Mahmoud, M. F. R. 2004. Studies on true spiders. Ph. D. thesis, Fac. of Agric. Fayoum. Cairo Univ., 188pp. 
Rahil, A. A. R. 2001. Relationship between field populations of true spiders and pests of maize at Fayoum governorate. Conf. of Sus. Agric. Devel., Fayoum Fac. of Agric., 185-194.

Stephanie N. and George, W. U. 2005. Mating frequency in Schizocosa ocreata (Hentz) wolf spiders: Evidence for a mating system with female monandry and male polygyny. Journal of Arachnology, 33(1):16-24.

$\mathrm{Wu}$, L.; Zhang, H. and He, T. 2013. Factors influencing sexual cannibalism and its benefit to fecundity and offspring survival in the wolf spider Pardosa pseudoannulata (Araneae: Lycosidae). Behav. Ecol. Sociobiol., 67: 205. 